\title{
Influence of Solar Wind Parameters on Equatorial Magnetic Observatories during Intense Geomagnetic Storms of the Year 2015
}

\author{
S. Joshi ${ }^{1,2 *}$ K. M. Rao ${ }^{1}$ \\ ${ }^{1}$ Institute of Seismological Research, Gandhinagar, Gujarat, India \\ ${ }^{2}$ Gujarat University, Ahmedabad, Gujarat, India
}

Received 26 August 2019, accepted in final revised form 14 January 2020

\begin{abstract}
Coronal mass ejection (CME) and Corotating interaction region (CIR), a dynamic phenomenon associated with the sun, is widely acknowledged as the main causative factor for the occurrence of the geomagnetic storms. In the present investigation, we studied the influence of solar wind parameters and interplanetary magnetic field (IMFBz) on two severe geomagnetic storms (Dst=<-200 nT) occurred during March and June 2015 using magnetic data recorded at four low latitude Indian magnetic observatories namely Jaipur (Rajasthan), Desalpar (Gujarat), Alibag (Maharastra) and Hyderabad (Telangana). Residual Hcomponent of magnetic field distinctly distinguish the different phases of storms. Solar wind density and pressure are more influencive factors during main phase of the magnetic storm with observed high MS coherence (>0.8) with the $\mathrm{H}$-comp. Dynamic spectrum of $\mathrm{H}$ component of magnetic field at low latitudes and solar wind parameters reveals a burst-like nature during the main phase of these storms. During Ionospheric Disturbance Dynamo (Ddyn) for March Storm, it is observed that American sector has downward movement in $\mathrm{H}$-component of magnetic field and prominent attenuation of EEJ in African and Indian sectors. Similarly, for June storm, downward H-component movement is observed in both the American and African sectors and attenuation of EEJ at Indian sector.
\end{abstract}

Keywords: H-component of magnetic field; Geomagnetic storm; Solar wind parameters; Interplanetary magnetic field; Ionospheric disturbance dynamo.

(C) 2020 JSR Publications. ISSN: 2070-0237 (Print); 2070-0245 (Online). All rights reserved. doi: http://dx.doi.org/10.3329/jsr.v12i3.42798

J. Sci. Res. 12 (3), 233-250 (2020)

\section{Introduction}

A geomagnetic storm is a multi-faceted phenomenon. Various solar phenomenon like solar wind plasma emissions and interplanetary magnetic field (IMF) are the main causative factors for the Geomagnetic storms [1]. Dynamics of ring currents and southward turning of the interplanetary magnetic field plays an important role during geomagnetic storm periods especially at equatorial magnetic observatories [2,3]. During

\footnotetext{
*Corresponding author: iamshivamjoshi@gmail.com
} 
geomagnetic storms, two physical processes takes place; one is, the direct penetration of polar cap electric field to the equator and second process is to take place the day after storm at the time of equatorial electro jets attenuation, auroral joule heating and ion drag acceleration which produces disturbance in wind [4]. Geomagnetic storms can be divided into the following stages: a) storms sudden commencement which corresponds to sudden increases in H-component of magnetic field; b) main phase which corresponds to sharp decrease in H-component of magnetic field and ring currents intensifies; c) recovery phase where H-component of magnetic field slowly rises to its normal value [5,6]. Types of storms can be decided based on maximum decreases in the Dst values. Based on Dst values, the magnetic storms are classified in four types. 1) Minor Strom (weak ones): Dst Index is up to $-50 \mathrm{nT}$; 2) Moderate Storm: Dst Index between -50 nT to -100 nT; 3) Major storm: Dst Index is $-100 \mathrm{nT}$ to $-200 \mathrm{nT}$; 4) Severe Storm: Dst Index is less than $-200 \mathrm{nT}$ [7]. Generally, solar wind pressure is normal at day side during the time of southward IMF and magnetic compression takes place during the time of northward IMF as enhancement in the solar wind pressure. Similarly, magnetic depression takes place on the night side [8].

Different current systems affect the different phase of magnetic storms [9]. The solar wind disturbance produced during magnetic storm can affect the whole current system including the ionospheric dynamo currents up to several hours to several days even after the end of magnetic storms [10]. This signature of ionospheric disturbance dynamo is observed through $\mathrm{H}$-component of magnetic field. Many times, it is noticed that continuous injection to the ring currents taking place; ring currents does not decay rapidly and resulting recovery phase of particular storms lasts one to two weeks. This kind of longer duration storms were termed as High-Intensity Long-Duration Continuous AE Activity events (HILDCAA events) [11]. The decreases in $\mathrm{H}$ filed during storm can longitudinally asymmetric. During HILDCAA events the ionospheric dynamo is likely to be disturbed more especially during the intense storms. However, the effect of ionospheric disturbance can be observed in the moderate storms too. The characteristics of geomagnetic storms at low latitudes station of Colaba (India) was first reported by Moos [12].

In the present paper, severe geomagnetic storms were potentially geo-effective and occurred during the solar activity period of current solar cycle-24 (Year 2015) are scrutinized. Mainly two severe geomagnetic storms and thirteen moderate and minor geomantic storms are occurred during year 2015. The main focus of the study is to understand the influence of the solar wind parameters, interplanetary magnetic field (IMFBz) and ionospheric disturbance on H-component of magnetic field during these magnetic storms. The statistical study has been performed to analyze two severe geomagnetic storms recorded at four low latitude magnetic observatories of India i.e. Jaipur (IIG, Rajasthan), Desalpar (ISR, Gujarat), Alibag (IIG, Maharashtra) and Hyderabad (NGRI, Hyderabad). Ionospheric Disturbance Dynamo (Ddyn) is also analysed for the American, African and Indian Sectors which fall under the equatorial region. 


\section{Data}

There are two intense storms occurred during 2015. First storm was occurred during March 17-18, 2015 (Dst=-223nT). This is the most intense geomagnetic storm (G4) of the current solar cycle and it is formally known as St. Patrick's Day Geomagnetic Storm and the second storm occurred during June 22-23, 2015 (Dst = -204 nT). The details of these storms are shown in Table 1.

Table 1. Details of Geomagnetic storm occurred during year 2015.

\begin{tabular}{|c|c|c|c|c|c|c|}
\hline Storm Time & SSC & Main Phase & $\begin{array}{l}\text { Onset of } \\
\text { Recovery phase }\end{array}$ & $\begin{array}{l}\text { End of } \\
\text { Recovery phase }\end{array}$ & Driver & $\begin{array}{l}\text { Type of } \\
\text { Storm }\end{array}$ \\
\hline $16-19$ & $16^{\text {th }}$ March & $17^{\text {th }}$ March & $17^{\text {th }}$ March & $18^{\text {th }}$ March & $\overline{\mathrm{CME}}$ & Intense \\
\hline 2015 & 07:29 UT & 05:20 UT & 19:02 UT & 06:00 UT & & storm \\
\hline 21-24 June & $21^{\text {nd }}$ June & $22^{\text {nd }}$ June & $23^{\text {th }}$ June & $24^{\text {th }}$ June & CME & Intense \\
\hline 2015 & 17:34 UT & 06:07 UT & 05:40 UT & 06:36UT & & storm \\
\hline
\end{tabular}

We used the magnetic data of four Indian stations (Jaipur (JAI), Desalpar (DSP), Alibag (ABG) and Hyderabad (HYB)), one American station (Honolulu (HON)) and one African station (Mbour (MBO)). The details of these magnetic stations and their data source are shown in Table 2. The sampling interval of horizontal magnetic field data of all these stations is one minute. The solar wind and IMF parameters are downloaded from the website of space physics data facility of NASA. Ionospheric disturbance is also plays an important role in the geomagnetic field variations. Ionospheric disturbance dynamo (Ddyn) for the two intense storms using three different sectors i.e., American (HON), African (MBO) and Indian (DSP) which are aligned in the same longitude is also studied and as shown in Fig. 1. Only day time signatures can be conjecture from the data in order to study ionospheric disturbance dynamo process. SYM-H, AU and AL indexes for each event were analyzed during the corresponding period.

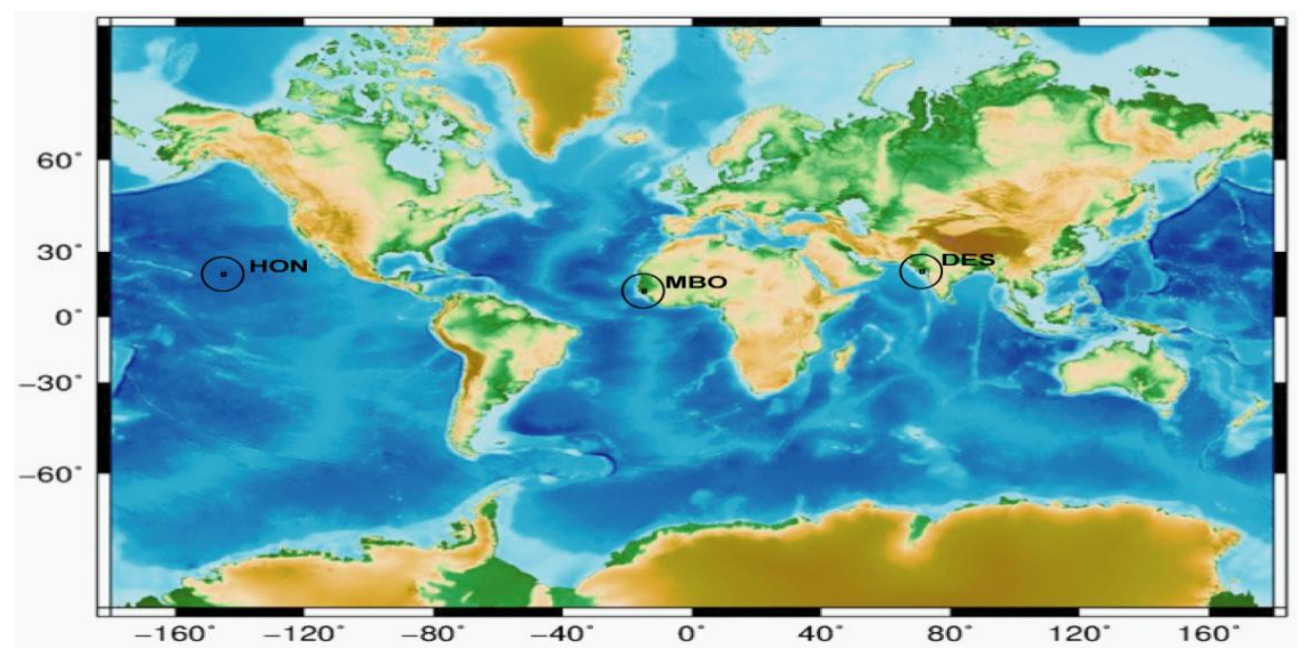

Fig. 1. Location of Magnetic observatories of $\mathrm{HON}, \mathrm{MBO}$ and DES. 
The SYM-H index represents the development of storm or different phases of storms. It is the influence of symmetric part of ring current present over the equatorial region. The $\mathrm{AU}$ index represent the strongest current intensity of the eastward or day time and the AL index represents westward or night time auroral electrojets. We deal with the sudden, sharp and short-lived depressions in the magnetospheric ring current and subsequent variations in solar parameters through $\mathrm{H}$-component of magnetic field. It is known that the intensity of solar parameters (e.g., solar flare, SEP flux etc.) is registered by satellite at the geostationary orbit in the near Earth space whereas the magnetic field variation and ring current depressions are recorded by a network of magnetic observatories well located all over the world.

Table 2. Details of Magnetic observatories.

\begin{tabular}{llllll}
\hline Obs. & Name \& & \multirow{2}{*}{ Obs. Region } & \multicolumn{2}{c}{ Geographical Coordinates } & \multirow{2}{*}{ Nata Source } \\
\cline { 4 - 5 } No. & Observatory ID & & Latitude & Longitudes & \\
\hline 1 & Jaipur(JAI) & Indian & 26.92 & 75.80 & Intermagnet \\
2 & Desalpar(DSP) & Indian & 23.74 & 70.69 & ISR \\
3 & Alibag(ABG) & Indian & 18.62 & 72.87 & Intermagnet \\
4 & Hyderabad(HYB) & Indian & 72.60 & 78.60 & Intermagnet \\
5 & Honolulu(HON) & American & 21.31 & 157.99 & Intermagnet \\
6 & Mbour(MBO) & African & 14.38 & 343.03 & Intermagnet \\
\hline
\end{tabular}

*ISR: Institute of Seismological Research, Gandhinagar, Gujarat, India

\section{Methodology}

\subsection{Residual H-component of magnetic field}

Firstly, quiet day variations of H-component are subtracted from the temporal variation of the horizontal component of magnetic field during the period of magnetic storm. In the second step, Dst index is subtracted from the resultant signal in order to reduce the ring current contribution from the ground magnetic field. Finally, the consequence signal is termed as the residual H-component of magnetic field for particular station. This methodology is applied on H-component of magnetic data of all the stations and the residual $\mathrm{H}$-component of all the stations for both the magnetic storms is determined.

\subsection{MS Coherence}

Magnitude squared coherence (MSC) can be applied on any two time series to find the frequency dependent measure of linear relation between these two time series. It is a function of frequency, and suggests that how good the $\mathrm{x}$ signal is corresponds to the $y$ signal and it always follows $0 \leq \operatorname{Cxy}(f) \geq 1$. Where $\operatorname{Cxy}(f)$ is the MS Coherence of the two given signals and can be given as,

$$
\operatorname{Cxy}(f)=\frac{|G x y(f)|^{2}}{\operatorname{Gxx}(f) G y y(f)}
$$


Where $G_{x y}(f)$ is the cross spectral density between $x$ and $y$, and $G_{x x}(f)$ and $G_{y y}(f)$ the auto spectral density of $x$ and $y$ respectively. The magnitude of the spectral density is denoted as $|\mathrm{G}|$. The detailed mathematical formulations for calculating MSC are given in references [13,14].

\subsection{Ionospheric disturbance dynamo}

During geomagnetic storms, $H$ component at low latitudes compromises quiet time variation of the earth's magnetic fields and disturbed magnetic field due to the geomagnetic storms.

$$
\mathrm{H}=\mathrm{S}_{\mathrm{R}}+\mathrm{D}
$$

Where, $S R$ is quiet time variation of Earth's magnetic field from the closest day to the magnetic storm. $D$ is disturbance in magnetic field. This disturbed magnetic field is incorporated with different current systems and can be represented as,

$$
D=\mathrm{D}_{\mathrm{R}}+\mathrm{D}_{\mathrm{CF}}+\mathrm{D}_{\mathrm{T}}+\mathrm{D}_{\mathrm{G}}
$$

Where, $D_{\mathrm{R}}$ represent the ring currents, $D_{\mathrm{CF}}$ are Chapmann Ferraro current, $D_{\mathrm{T}}$ show the magnetospheric tail current and $D_{\mathrm{G}}$ stands for the magneto telluric currents which are negligible. Now $D_{\mathrm{R}}, D_{\mathrm{CF}}$ and $D_{\mathrm{T}}$ are including in the ring current system, from which only the symmetric part of the ring current is consider, so $D$ is given as,

$$
\mathrm{D}=\operatorname{Sym} \mathrm{H} * \operatorname{Cos}(\mathrm{L})
$$

Where Sym $H$ is the symmetric $H$ index and $L$ is the magnetic latitude of the station. Now to calculate the ionospheric disturbance dynamo, only the day time signature from the data is taken and it is calculated as,

$$
\text { Ddyn }=H-S_{\mathrm{R}}-\operatorname{Sym} H * \operatorname{Cos}(\mathrm{L})
$$

\section{Results and Discussion}

\subsection{Variation of solar wind parameters during intense geomagnetic storms}

Various solar wind structures such as bidirectional electron fluxes [15], interplanetary shocks [16], magnetic cloud [17] and ejections with nearby magnetic field structure play an important role in the intensity of storms [18]. In order to see the general characteristics of 17 March 2015 storm, we plotted H-component of magnetic field, Global Dst and solar wind parameters (Density $(\mathrm{n} / \mathrm{cc})$, Velocity $(\mathrm{Km} / \mathrm{s})$, Flow Pressure $(\mathrm{nPa})$ ) and $\mathrm{Bz}$ component of interplanetary magnetic field (IMF Bz) during 16-19 March, 2015 are plotted and shown in (Fig. 2(a)). From this figure, it is explicit that all the solar wind parameters are enhanced exactly during the occurrence of shock wave. On $17^{\text {th }}$ March, two consecutive decreases is comprehensible on H-component of magnetic field during the main phase of the storm. This storm begun with the SSC on $16^{\text {th }}$ March at 07:29 UT; compression in SW parameters and southward IMF Bz is noticeable. 

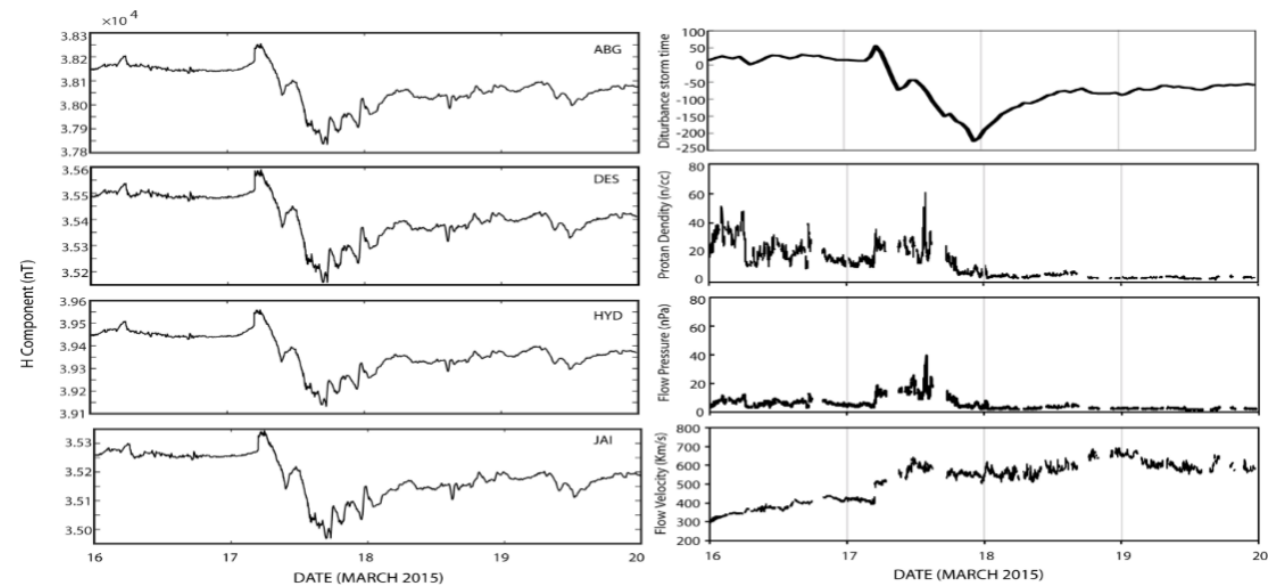

Fig. 2(a). Variation of H component of ABG, DES, HYD and JAI (left) and Variation of Dst, solar wind parameters (Proton Density (n/cc), Flow pressure and Flow velocity) during 16-20 March 2015 (right).

The occurrence of main phase takes place on $17^{\text {th }}$ March at 05:20 UT. All the SW parameters are at its highest point during the southward IMF Bz having maximum value of $-25.98 \mathrm{nT}$ on $17 \mathrm{March}$. SW speed is raised to $609 \mathrm{Km} / \mathrm{s}$, SW pressure is $39.23 \mathrm{nPa}$ and $\mathrm{SW}$ density is $60.54 \mathrm{n} / \mathrm{cc}$ during the main phase of the storm. IMF Bz is oscillated maximum northward and southward during the main phase. Recovery phase started at 19:02 UT on $17^{\text {th }}$ March and lasted for several days up to $26^{\text {th }}$ March 2015. No remarkable feature observed during the recovery phase of the storm which is commonly observable phenomenon. Based on its characteristics, the March 2015 storm is considered as a severe storm which is the result of coronal mass ejection from the Sun. Moreover, this is the first most intense storm of the year 2015 of solar cycle 24 during solar maximum. Mostly, the CMEs generate intense geomagnetic disturbance which produces intense magnetic storms [19]. CIR produces moderate and minor kind of magnetic storms [20].

The June storm is CME driven which is second intense storm of the year 2015 (Fig. 2b). The SSC observed at 17:34 UT on $21^{\text {st }}$ June, sudden enhancement is observed in all the SW parameters at the time of shock wave. The main phase is noticed on $22^{\text {nd }}$ June at 06:07 UT, solar wind speed raised to $792.90 \mathrm{Km} / \mathrm{sec}$, SW density raised to $71.21 \mathrm{n} / \mathrm{cc}$, SW pressure enhanced up to $59.86 \mathrm{npa}$ and IMF Bz reached to maximum southward of -40.17 nT. IMF Bz is oscillated maximum northward and southward during the main phase. The recovery has started at 05:40 UT on $22^{\text {nd }}$ June and ended at 06:36 UT on $23^{\text {rd }}$ June. 

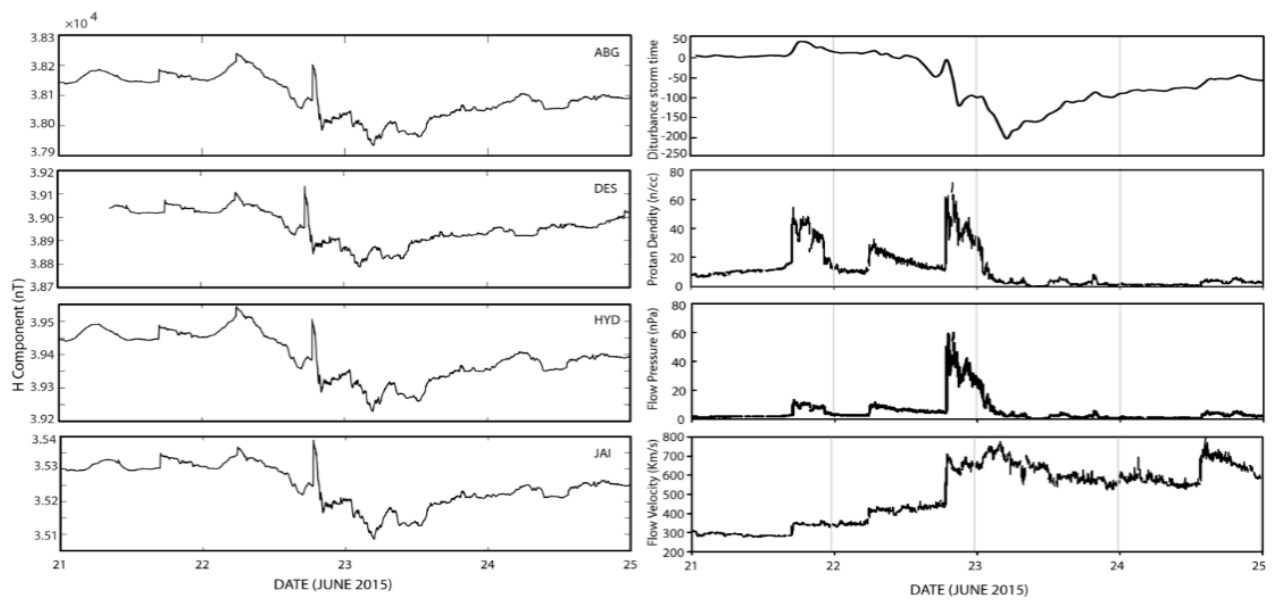

Fig. 2(b). Variation of H component of ABG, DES, HYD and JAI (left) and Variation of Dst, solar wind parameters (Proton Density (n/cc), Flow pressure and Flow velocity) during 21-25 June 2015 (right).

The characteristics of storms such as different phases, their onset time and driving force of particular storm are shown in Table 1. SW pressure and density are found to be more affecting parameters on H-component of magnetic field of the equatorial magnetic observatories. As the longitudinal distance from each observatories of India is not large, the influence of the solar wind parameters on all the observatories is found to be similar. Similar results were reported earlier, especially prominent influence of SW dynamic pressure while studying SW parameters during intense magnetic storms on $\mathrm{H}$-component of magnetic field at ground based observatories of low and high latitudes [21].

\subsection{Magnitude square coherence analysis}

In order to identify most influential solar wind parameter on effecting the observed horizontal magnetic field on the ground, we carried out the magnitude squared coherence analysis between solar wind parameters and $\mathrm{H}$-component of magnetic field. This analysis is generally applied to calculate the likeness in the frequency of two signals. The time series of four days data with a total 5760 points length with the sampling rate of $1 \mathrm{~min}$ is used to calculate the MS coherence between ground based horizontal magnetic field of Hyderabad observatory and Solar wind parameters, which includes density, pressure, velocity, temperature and Interplanetary magnetic field component IMF Bz. 


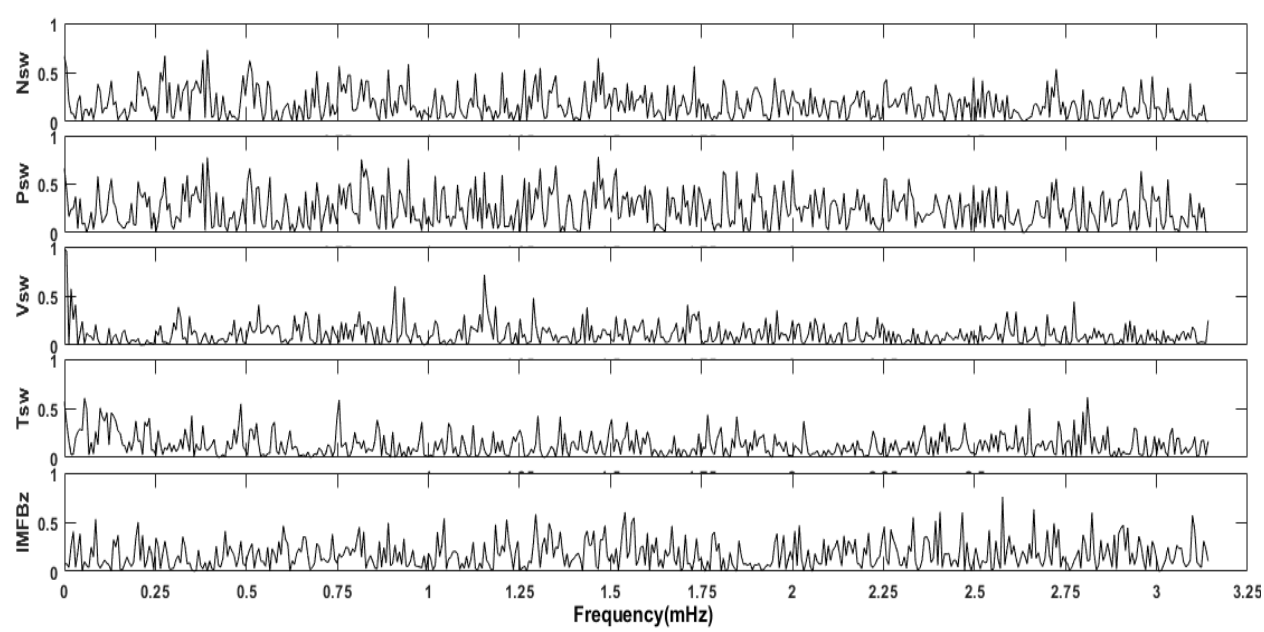

Fig. 3(a). Magnitude Squared Coherence analysis of $\mathrm{H}$-field variation with solar wind and IMF Bz Parameters during March 2015 Storm.

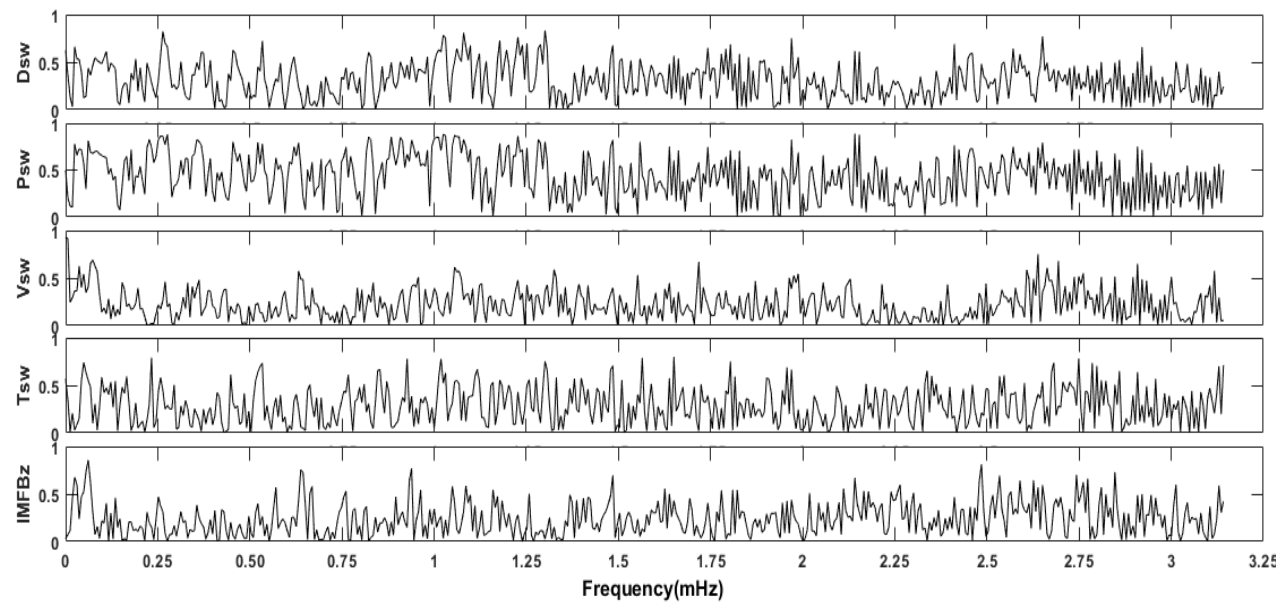

Fig. 3(b). Magnitude Squared Coherence analysis of H-field variation with solar wind and IMF Bz Parameters during June 2015 Storm.

Figs. 3a and $3 \mathrm{~b}$ show the MS coherence of H-component of magnetic field to each SW parameter for March and June storm respectively. In this Fig., starting from first panel to fifth panel, plot represents the MS coherence with density, pressure, velocity, temperature and IMF Bz respectively. It is observed from the above section that SW parameters have direct influence on observed ground magnetic field. Here also, similar observation for both the storms, such as Tsw and Vsw are found to have good coherence of 0.60 , whereas, IMFBz is having the coherence of 0.70. Among all the SW parameters, Nsw and Psw are found to be maximum coherence of $>0.85$ which is observed in almost all the frequencies. This characteristic reveals the fact that SW density and pressure are more influencive in 
comparison with other SW parameters. It is reported that changes in the IMF field remarkably effect the geomagnetic field changes in all the three latitudinal regions during all the kind of storms, adding to this variation of geomagnetic field is high at high latitudes in comparison with low and mid latitudes [22]. Further, the influence of solar wind parameters on geomagnetic field is reported by many researchers [23,24].

\subsection{Proximity between residual H-component of magnetic field and solar wind parameters}

In this section, the residual H-component of magnetic field during two intense geomagnetic storm events occurred in March and June 2015 are determined. One-minute data of H-component magnetic field at four magnetic observatories of India namely Jaipur (JAI), Desalpar (DSP), Alibag (ABG) and Hyderabad (HYB) is analysed. The data of four complete days (96 hours) are considered, which in general, comprises SSC, initial, main and recovery phases of magnetic storm. It is reported in previous studies that the small scale magnetic field variation can be removed from $\mathrm{H}$-component magnetic field, if, quiet time ionosphere currents and Dst variations are eliminated from $\mathrm{H}$-component magnetic field [25]. Quiet time ionosphere currents and Dst variations are considered as a natural background and these background value from $\mathrm{H}$-component are removed to get residual H-component magnetic field.

(a)

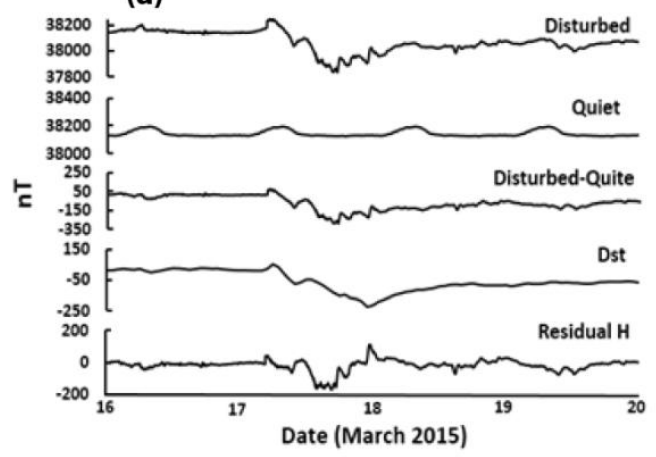

(b)

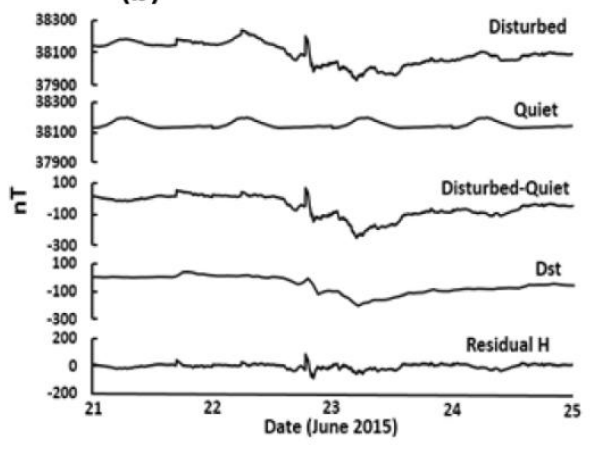

Fig. 4. Derivation of Residual-H for (a) March storm and (b) June storm recorded at Alibag Observatory.

The Fig. 4 depicts this entire process of deriving the residual $\mathrm{H}$-component of magnetic field of Alibag station. In this Fig., the $1^{\text {st }}$ panel shows temporal variation of the horizontal component of magnetic field at Alibag during the 16-19 March 2015 (Fig. 4a) and 21-24 June 2015 (Fig. 4b). The $2^{\text {nd }}$ panel shows the variation of $\mathrm{H}$ - component at Alibag during first quiet day of the month, which is $10^{\text {th }}$ March for March event and $20^{\text {th }}$ June for June event. The $3^{\text {rd }}$ panel is obtained by subtracting $2^{\text {nd }}$ panel from first one. It shows the variation after removal of quiet day pattern from the disturbed day variation. The $4^{\text {th }}$ panel is Dst-index during the event. The $5^{\text {th }}$ panel is residual H-component of 
magnetic field which is obtained by subtracting the Dst Index from derived signal of $3^{\text {rd }}$ panel. Since Dst is in hourly index and the ground magnetic data is one minute sampling interval, Dst index is interpolated. After removal of Dst, one can assume that the long period ring current contribution from the ground magnetic field data is eliminated. It is found that solar wind density is more infliencial parameter on observed $\mathrm{H}$-component magnetic field. Similar results are observed in previous studies; solar wind density is more influencial parameter on observed H-component magnetic field in comparison with other SW parameters during the storms [26,27]. A detailed description of the SW parameter and magnetic storm correlation is discussed in previous section (4.1). Further, residual Hcomponent of magnetic field of all the four stations for both these storms and depicted in Figs. 5a and $5 b$.

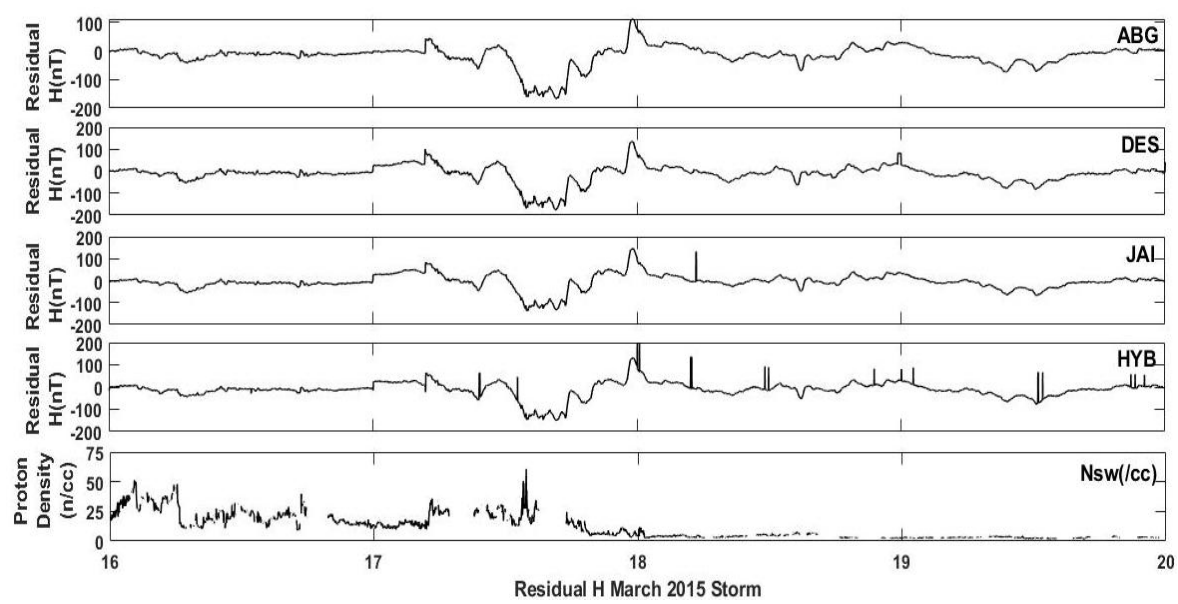

Fig. 5a. Residual H plot for four magnetic observatories with Proton Density during March 2015 storm.

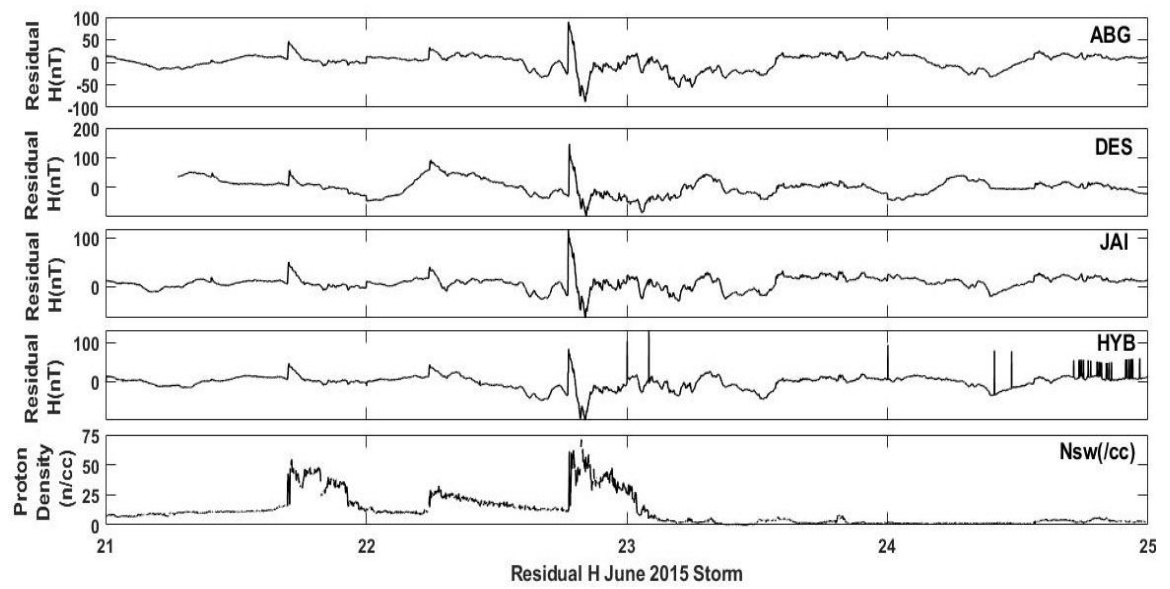

Fig. 5b. Residual H plot for four magnetic observatories with Proton Density during June 2015 storm. 
Here, Figs. 5a and 5b show the comparison of SW density with residual $\mathrm{H}$ plot (observed-quiet-Dst) during March and June 2015 storm respectively. SSC (16 ${ }^{\text {th }}$ March), main phase $\left(17^{\text {th }}\right.$ March) and recovery phase $\left(19^{\text {th }}\right.$ March $)$ of the storms are distinctly conspicuous in residual H-component of magnetic field. The SSC and main phase are greatly influenced by SW density. However, the recovery phase has little variation. Similarly, SSC ( $21^{\text {st }}$ June) and main phase $\left(22^{\text {nd }}\right.$ June $)$ during the June storm with high enhancement in the SW density is evident. It is seen that the recovery phase ( $24^{\text {th }}$ June) has quiet natural variation during storm. Comparison of residual $\mathrm{H}$ and SW density reveals the direct influence on $\mathrm{H}$-component magnetic field of ground based magnetic observatories.
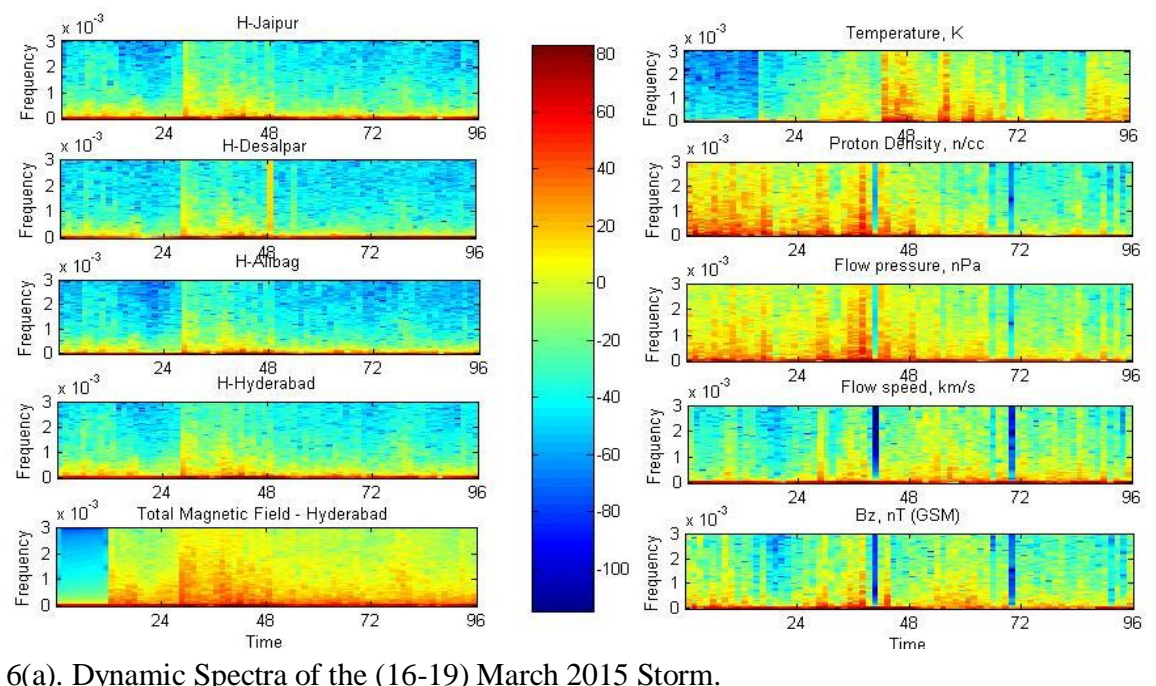

Fig. 6(a). Dynamic Spectra of the (16-19) March 2015 Storm.
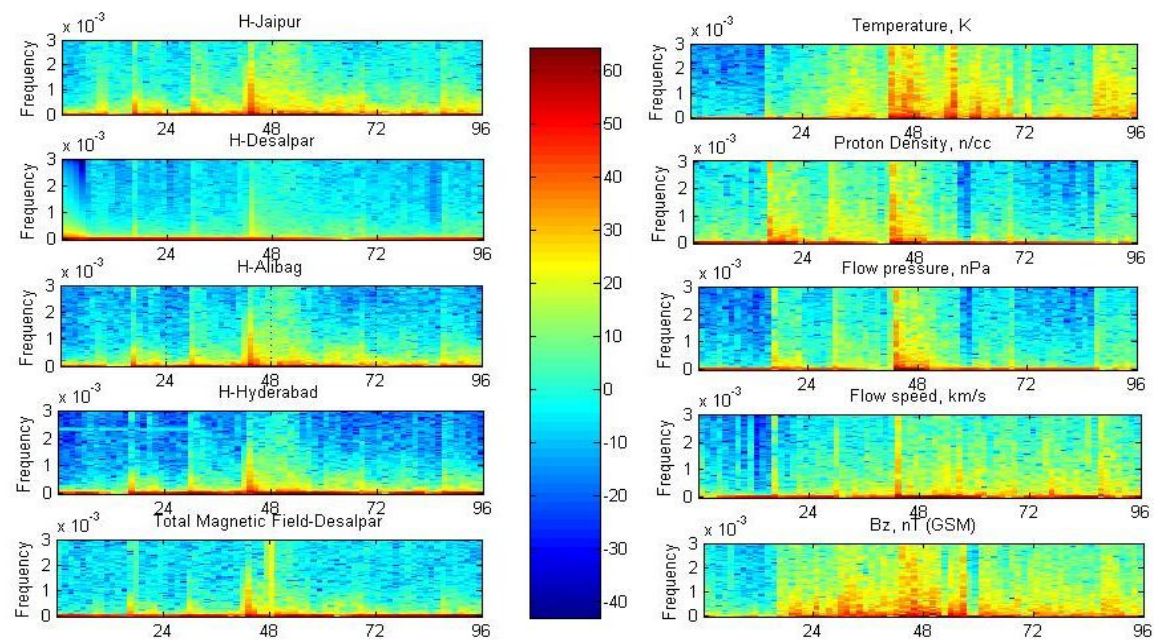

Fig. 6(b). Dynamic Spectra of the (21-24) June 2015 Storm. 
In order to identify the signal strength over time at various frequencies for different phases of the storms, the spectrogram of both the storms are plotted and shown in (Figs. 6a and 6b). During March storm (Fig. 6a), a burst-like nature is observed between 17-18 March on observed horizontal magnetic field at four observatories (left side panel) and the similar bursts also observed in SW parameters including IMF Bz (right side panel). It is clearly evident that this portion represents the main phase of the storm. SW density and pressure are seems to be more bustling from the beginning of the SSC (16 ${ }^{\text {th }}$ March) to recovery phase $\left(19^{\text {th }}\right.$ March) whereas other SW parameters such as SW Temperature, SW speed and IMF Bz are dynamic only during the main phase of the storm. Earlier studies also found such bursts in the dynamic spectra of $\mathrm{H}$-component of magnetic field and solar wind parameters [28]. Similarly for June event (Fig. 6b), the bursts during the main phase of the storm is perceptible from the SW parameters and $\mathrm{H}$ magnetic field variation. SW density, SW pressure and IMF Bz are found vigorous during all the phases of magnetic storm. SW parameters and variation of $\mathrm{H}$-component of magnetic field distinguish, onset of SSC and stable nature is observed during the recovery phase of the storm. Since solar wind produce the disturbance in the magnetic field, an enhancement in the form of burst is seen in the spectrograms of both the storms. Further, one can distinguish the different phases of the storms on the basis of such burst like enhancement during the entire storm period.

\subsection{Ionospheric disturbance dynamo}

The effects of all currents flowing in the earth's environment integrate with the earth's magnetic field. The connection of large scale high and low latitude current system is attributable to two main physical processes: 1) direct prompt penetration: It takes place mostly at the equatorial latitudes, and it is the sum of convection electric field and over shielding electric field. It is generally observed that convection electric field is vital during main phase of the storm and over shielding electric field is vital during recovery phase of the storm [29,30]. 2) Ionospheric disturbance dynamo: It is a consequence of convection electric field and thermospheric wind dynamo [31]. In the present study, we focused only on Ionospheric disturbance dynamo, a significant phenomenon related to the geomagnetic storms. The ionospheric disturbance dynamo process is still continued even after completion of the magnetic storm. So, the effect continues on a quiet day during the recovery phase and even after, it creates the magnetic disturbance in the Ionosphere.

Here firstly, several parameters such as daily regular variation, Chapman Ferraro Currents, Tail currents, Symmetric or asymmetric ring currents and ground telluric currents are evaluated in order to calculate the equatorial magnetic signature of the ionospheric disturbance dynamo during two intense storms in March 2015 and June 2015. Variation of interplanetary parameters and magnetic indexes for March 2015 and June 2015 storms are shown in Fig. 7. Dayside aroral electrojets represented by AU and night side denoted by AL and are shown in the first and second panel in Fig. 7. The intensification of the westward ring current in the equatorial region of the magnetosphere near the earth resulted in the decrease of Sym-H index which showed a minimum value of 
around $-240 \mathrm{nT}$ on 17 March 2015 (left side) and $-210 \mathrm{nT}$ on $23^{\text {rd }}$ June 2015 which are shown in the third panel in Fig. 7.
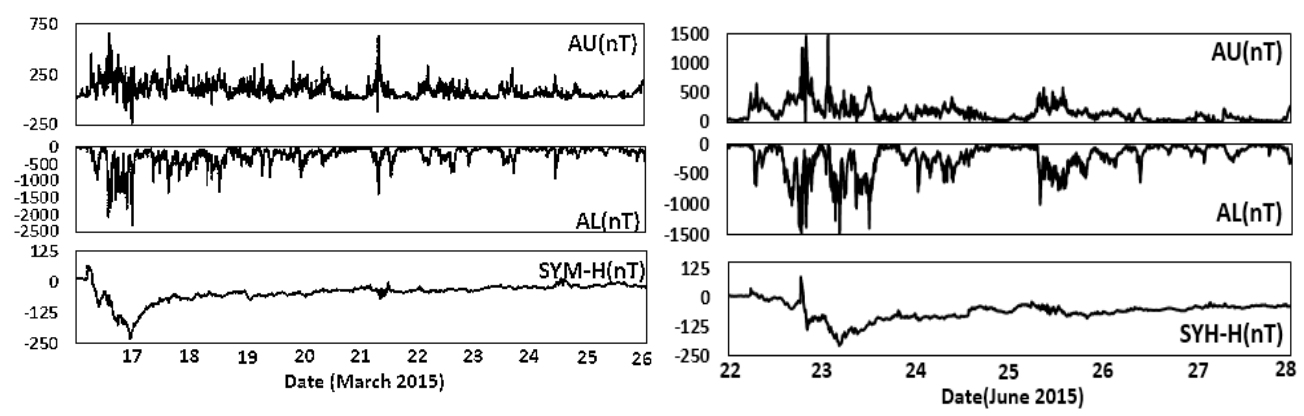

Fig. 7. Interplanetary parameters and magnetic indexes for the March 2015 storm (left side) and June 2015 storm (right side).

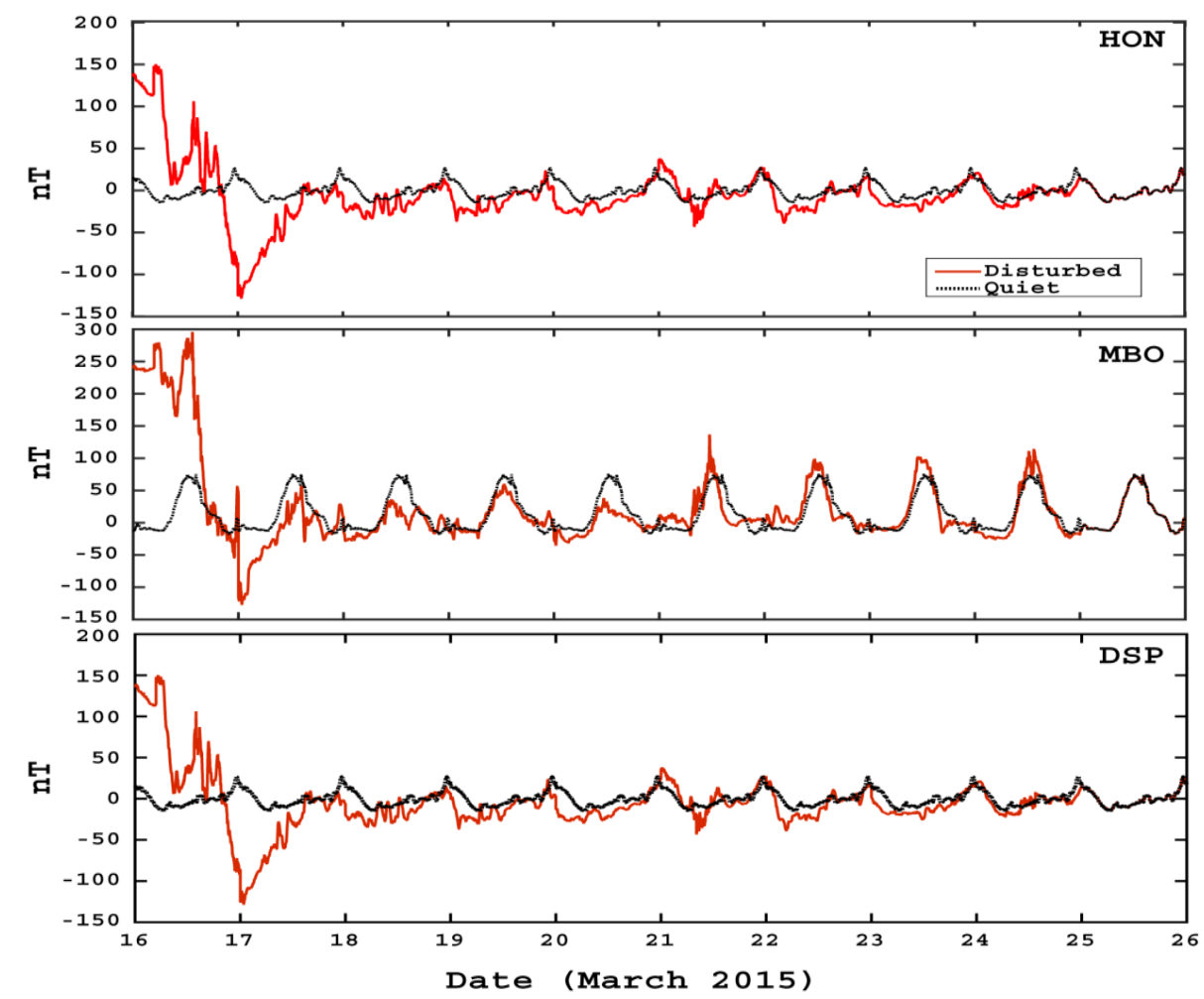

Fig. 8. Variation of the H component of the Earth's magnetic field (red lines) observed at different stations on March 2015 storm and superimposed black lines on the full lines for variation of the $\mathrm{H}$ component during the closest quiet day chosen as a reference day.

While choosing to directly calculating the ionospheric disturbance dynamo, the variation of raw $\mathrm{H}$ component at three equatorial regions is chosen, in terms of disturbed 
and quiet condition during the time of March storm, especially at the time of recovery phase i.e., 16 to 26 March 2015. It is district that recovery phase started on 19:02 UT on the $17^{\text {th }}$ March and lasted for several days up to $26^{\text {th }}$ March 2015. Upto $25^{\text {th }}$ March, the enhanced amplitude is seen in all three regions due to the magnetic disturbance. So $25^{\text {th }}$ March is selected as a nearest quiet day after recovery phase of the magnetic storm. Fig. 8 shows the disturbance time (Red lines) and super-imposed black lines represent the quiet time variation of $25^{\text {th }}$ March.

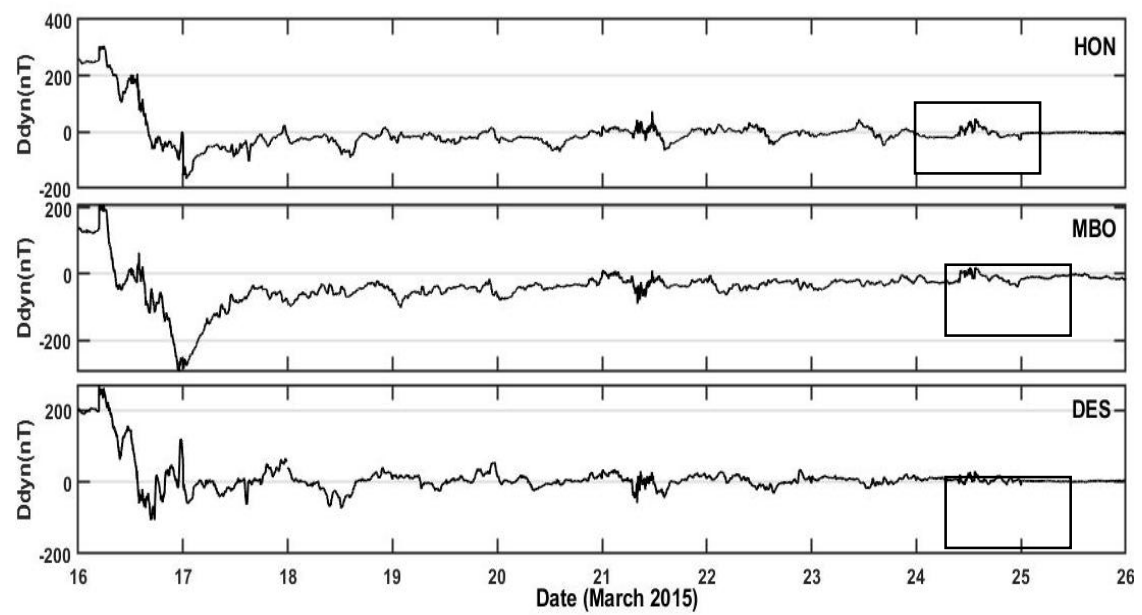

Fig. 9. Variation of the H component disturbance Ddyn during March 2015 Storm

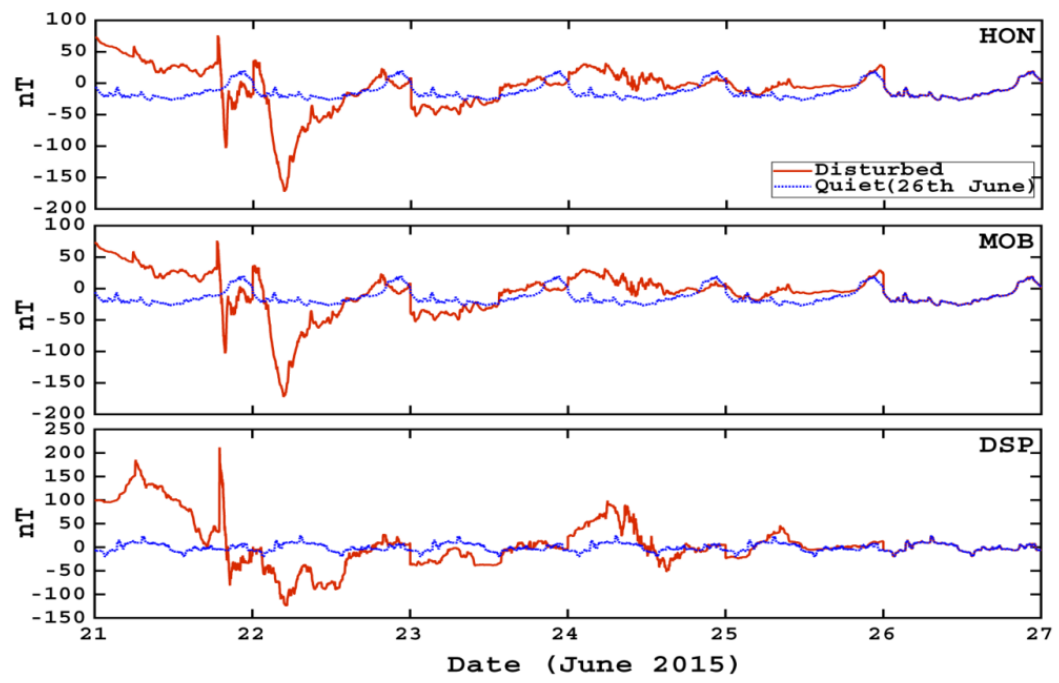

Fig. 10. Variation of the H component of the earth's magnetic field (red lines) observed at different stations on June 2015 storm and superimposed black lines on the full lines for variation of the $\mathrm{H}$ component during the closest quiet day chosen as a reference day. 
Fig. 9 shows the Ddyn component for the March storm which is derived from the $\mathrm{H}$ component of the magnetic field in American sector (HON), African sector (MBO) and in Indian sector (DES). On $23^{\text {rd }}$ March, Ddyn effect is denoted as rectangle at American sector which is not seen in the African and Indian sector and the equatorial activity is unlike American sector. The attenuation of equatorial electrojets in African and Indian sectors is noticeable. The westward movement is due to the electric filed convection on $21^{\text {st }}$ March. The similar procedure has been applied to calculate the Ddyn component for the June storm. Variation of raw $\mathrm{H}$ component at three equatorial regions, in terms of disturbed and quiet condition during the time of June storm is analysed having time span of 6 days i.e. $21^{\text {st }}$ to $26^{\text {th }}$ June 2015. Fig. 10 shows the disturbance time (Red lines) and superimposed black lines represent the quiet time variation of $26^{\text {th }}$ June.

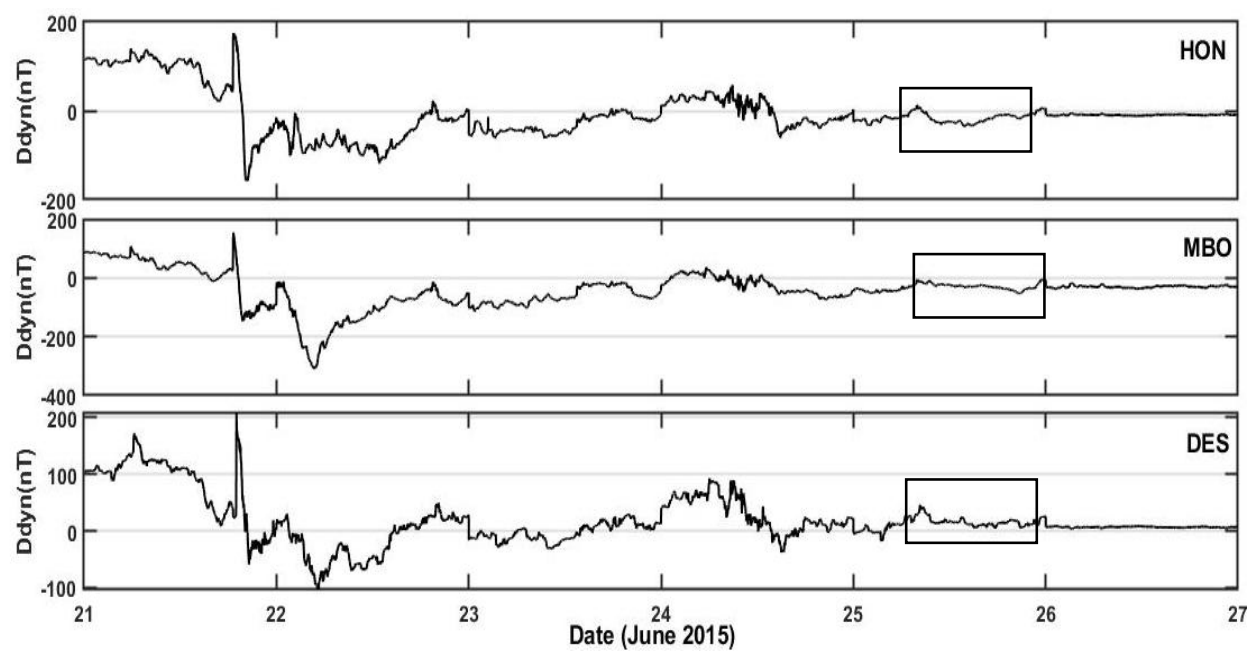

Fig. 11. Variation of the H component disturbance Ddyn during June 2015 Storm.

Fig. 11 depicts the Ddyn component for the June storm, derived from the $\mathrm{H}$ component of the magnetic field in American sector (HON), African sector (MBO) and Indian sector (DES). Convection of electric field into the dawn-dusk directed magnetosphere is observed on $25^{\text {th }}$ June, Ddyn effect is denoted as rectangle. A southward H-component of magnetic field movement is observed in the American and African sectors and the attenuation of equatorial electrojets is negligible in Indian sector. While studying Ddyn of several storms, it is reported that, 1) Signature of Ddyn is strongly dependent on magnitude of magnetic storm, onset of magnetic storm and duration of storms. 2) Ddyn is strong at American sector (-100 nt); African sector has influence of eastward current (unusual in Ddyn) and Ddyn effect is not significant due to attenuation of equatorial electrojets at Asian sector for 23-24 September 2001 storm; attenuation of equatorial electrojets can vary for different longitudinal station [32]. Moreover, this study reported that all the storms have shown the attenuation of equatorial electrojets similar to observation made in our study. 


\section{Conclusion}

Two intense geomagnetic storms which occurred during the year 2015 are investigated. We analysed horizontal component of magnetic field, Global Dst and solar wind parameters including Density (n/cc), Velocity $(\mathrm{km} / \mathrm{s})$, and Bz component of interplanetary magnetic field (IMF $(\mathrm{Bz})$ ) during the time period of two intense geomagnetic storms i.e. March 16-19 and June 21-24. All the SW parameters are at its highest point during the southward IMF Bz, having maximum value of $-25.98 \mathrm{nT}$ for March storm and $-40.17 \mathrm{nT}$ for June storm. In order to delineate the information of small scale magnetic field, the residual H-component of magnetic field is derived. It enables us to directly identify SSC and main phase of magnetic storm and allow to understand the influence of the SW parameters. Here, it is found that SW density is more dominant than other SW parameters. Similar results are found during the analysis of magnitude squared coherence. The MS coherence of Tsw and Vsw with H-component of magnetic field is 0.60 whereas with IMFBz is 0.70 . Among all the SW parameters, Nsw and Psw are found to be maximum coherence of $>0.85$ for all the frequencies. In dynamic spectrum of storms, a burst-like nature is noticeable during the main phase of both the storms. Equatorial magnetic signature of the ionospheric disturbance dynamo at three different longitudinal sector i.e. American sector (HON), African sector (MBO) and Indian sector (DES) for two intense storms is interpreted. Firstly, the variation of raw H-component of magnetic field at three equatorial regions, in terms of disturbed and quiet conditions is analysed. For March storm, African and Indian sector has experienced the attenuation of equatorial electrojets and in American sector downward movement is seen. For June storm, a southward H component movement is observed in the American sector and African sector and attenuation of equatorial electrojets is negligible in Indian sector.

\section{Acknowledgment}

The authors are thankful to the Director General and the Director of Institute of Seismological Research (ISR) for their encouragement in new study from the institute and permitting us to publish work. We are grateful to the WDC Kyoto team; OMNI team and INTERMAGNET project for open access to their valuable data. We are thankful to $\mathrm{K}$. Arora, Principal Scientist, CSIR-NGRI for her kind guidance to initiate the geomagnetic storm study.

\section{References}

1. S. Kumar and A. Raizada, J. Phys. 71, 1353 (2008). https://doi.org/10.1007/s12043-008-0189-7

2. W. D. Cramer, N. E. Turner, M.-C. Fok, and N. Y. Buzulukova, J. Geophys. Res.: Space Phys. 118, 1062 (2013). https://doi.org/10.1002/jgra.50138

3. Y. I. Feldstein, V. Yu. Pisarskij, A. Prigancová, and P. Ivanova, Studia Geophysica et Geodaetica, 34, 129 (1990). https://doi.org/10.1007/BF02295832 
4. J. Bulusu, R. K Archana, K. Arora, N. P. Chandrasekhar, and N. Nagarajan, J. Geophys. Res.: Space Phys. 123, 6821 (2018). https://doi.org/10.1029/2018JA025247

5. G. Vichare, S. Alex, and G. S. Lakhina, J. Atmos. Sol.-Terr. Phys. 71, 1814 (2009). doi:10.1016/j.jastp.2009.06.015

6. A. G. Hafez, E. Ghamry, H. Yayama, and K. Yumoto, Adv. Space Res. 51, 39 (2013). https://doi.org/10.1016/j.asr.2012.07.035

7. C. A. Loewe and G. W. Prolss, J. Geophys. Res. 102, 14209 (1997). https://doi.org/10.1029/96JA04020

8. D. -Y. Lee and L. R. Lyons, J. Geophys. Res. 109, A04201 (2004). https://doi.org/10.1029/2003JA010076

9. N. Fukushima and Y. Kamide, Rev. Geophys. 11, 795(1973). https://doi.org/10.1029/RG011i004p00795

10. M. L. Huy and C. A.-Mazaudier, J. Geophys. Res. 113, A02312 (2008). https://doi.org/10.1029/2007JA012686

11. B. T. Tsurutani and W. D. Gonzalez, The Interplanetary Causes of Magnetic Storms: A Review, ed. B. T. Tsurutani (AGU, Washington, D. C (1997) pp. 77-89. https://doi.org/10.1029/GM098p0077

12. N. A. F. Moos (Government Central Press, Bombay, 1910).

13. D. Ramırez, J. Via, and I. Santamarı - Acoustics, Speech, and Signal Processing, Int. Conf. on March, 3769 (2008). https://doi.org/10.1109/ICASSP.2008.4518473

14. G. C. Carter, C. H. Knapp, and A. H. Nuttall, IEEE Transactions on Audio and Electroacustics 21, 331 (1973). https://doi.org/10.1109/TAU.1973.1162496

15. J. T. Gosling, D. N. Baker, and S. J. J. Bame, J. Geophys. Res. 92, 8519 (1987). https://doi.org/10.1029/JA092iA08p08519

16. M. H. Farris, C. T. Russell, M. F. Thomsen, and J. T. Gosling, J. Geophys. Res. 97, 19121, (1995). https://doi.org/10.1029/92JA01976

17. L. F. Burlaga, L. Klein, N. R. Sheeley, D. J. Michels, R. A. Howard, M. J. Koomen, R. Schwenn, and H. Rosenbauer, Geophys. Res. Lett. 9, 1317 (1982). https://doi.org/10.1029/GL009i012p01317

18. L. F. Burlaga, J. Geophys. Res. 106, 15917 (2001). https://doi.org/10.1029/2000JA000107

19. A. J. Hundhausen, J. Geophys. Res. 98, 177 (1993). https://doi.org/10.1029/93JA00157

20. C. Fathy, A. A.-Mazaudier, A. M. Fathy, K. Mahrous, Yumoto, and E. Ghamry, J. Geophys. Res. Space Physics 119, 4120 (2014). https://doi.org/10.1002/2013JA019510

21. U. Villante, P. Francia, S. Lepidi, D. M. Lauretis, E. Pietropaolo, L. Cafarella, A. Meloni, A. Lazarus, R. Lepping, and F. Mariani, Geophys. Res. Lett. 25, 2593 (1998). https://doi.org/10.1029/98GL00335

22. S. bhardwaj, P. A. Khan, R. Atulkar, and P. K. Purohit, J. Sci. Res. 10, 133 (2018). https://doi.org/10.3329/jsr.v10i2.34509

23. G. I. Korotova and D. G. Sibeck, J. Geophys. Res. 100, 35 (1995). https://doi.org/10.1029/94JA02296

24. C. T. Russell, M. Ginskey, S. Petrinec and F. Le, Geophys. Res. Lett. 19, 1227 (1992). https://doi.org/10.1029/92GL01161

25. P. Francia, S. Lepidi, U. Villante, P. D. Giuseppe, and A. J. Lazarus, J. Geophys. Res. 104(A9), 19923 (1999). https://doi.org/10.1029/1999JA900229

26. S. Balveer, Rathore, C. Subhash, K. A. Kaushik, D. C. Firoz, A. K. Gupta, Shrivastava, K. K. Parashar, and R. M. Bhaduriya, Int. J. Appl. Phys. Math. 1, 149 (2011). https://doi.org/10.7763/IJAPM.2011.V1.29

27. G. Vichare and S. Alex, Solar Influence on the Heliosphere and Earth's Environment: Recent Progress and Prospects. Goa (2006) pp. 245. https://cdaw.gsfc.nasa.gov/publications/ilws_goa2006/

28. G. Vichare, S. Alex, and G. S. Lakhin, J. Atmos. Sol. -Terr. Phys. 71, 1814 (2009). https://doi.org/10.1016/j.jastp.2009.06.015 
29. B. G. Fejer, C. A. Gonzales, D. T. Farley, M. C. Kelley, and R. F. Woodman, J. Geophys. Res. 84, 5797 (1979). https://doi.org/10.1029/JA084iA10p05797

30. T. Kikuchi K. H. Hashimoto and K. Nazoki, J. Geophys. Res. 113, A06214 (2008). https://doi.org/10.1029/2007JA012628

31. M. Blanc and A. D. Richmond, J. Geophys. Res. 85, 1669 (1980). https://doi.org/10.1029/JA085iA04p01669

32. M. L. Huy and C. A. Mazaudier, J. Geophys. Res.: Space Phys. 32, A10301 (2005). https://doi.org/10.1029/2004JA010578 